about not offending advertisers, owners or boards? It sounds about as sophisticated as an anti-newspaper public relations person would have her believe.

What we have then is a conspiratorial view of the American science press; a view that suggests that American science journalists - undifferentiated by Professor Nelkin - are captives of the scientific establishment either because they are in awe of scientists or are intimidated by them. A view that suggests further that the scientific establishment, thereby, escapes the critical scrutiny that is afforded almost every other institution in the United States. A view that holds the American press buys what science sells and asks no questions.

"Scientists", Professor Nelkin con- cludes, "must restrain the promotional tendencies that lead to controls on information or to oversell, and they must open their doors to more probing investigation. And journalists on their part must try to convey understanding as well as information. It is not enough to merely react to scientific events, translating and elucidating them for popular consumption..." (p.182). How else, she asks in this book, can the unwashed public understand the social, economic and political impact of science and technology on their lives and livelihoods?

Howard Simons, formerly a science writer and Managing Editor of The Washington Post, is Curator of the Nieman Fellowships for Journalists, Harvard University, I Francis Avenue, Cambridge, Massachusetts 02138, USA.

\section{Simian affairs}

\section{John C. Mitani}

Apes of the World: Their Social Behavior, Communication, Mentality and Ecology. By Russell H. Tuttle. Noyes Publications, Park Ridge, New Jersey 07656: 1987. Pp.421. \$55.

SixTy years ago, few data existed regarding the behaviour and ecology of our closest living relatives, the apes. In 1929 Robert and Ada Yerkes summarized available information in a seminal volume, The Great Apes. The intervening years have witnessed rapid growth in laboratory and field studies that have contributed substantially to our understanding of the behavioural ecology of gibbons, orangutans, chimpanzees, bonobos and gorillas. Russell Tuttle ably compiles results of recent research in Apes of the World.

Tuttle, following the topical guide provided by the Yerkes, presents readable and succinct accounts of taxonomy, locomotion, feeding, nesting, tool use, cognition, communication and sociobiology. His coverage of each subject is thorough, and his summaries of relevant research are written with care and accuracy. Readers searching for information on virtually every aspect of ape behaviour will be able to find a clear, concise statement in this book. Where empirical studies are currently lacking, Tuttle points constructively to future lines of research. The reference list is extensive, and those wishing to consult the primary literature will find Apes of the World an indispensable guide.

The close phylogenetic relationship between apes and humans ensures that the study of ape behavioural ecology will be of particular interest to researchers applying the comparative approach to reconstruct the evolution of human behaviour. Tuttle, a palaeoanthropologist, has written this book for students and researchers concerned with this problem. Small samples, coupled with reluctance to perform field experiments, limit generalizations about ape behaviour made by primatologists, and models of human evolution based on uncritical acceptance of these generalizations run the risk of oversimplification. Tuttle clearly separates fact from fiction, and his prudent exposition should aid palaeoanthropologists who seek to use results of ape field research to understand human behavioural evolution.

Although Tuttle's lucid treatment is packed with up-to-date information on ape behaviour, Apes of the World fails to integrate or to interpret. Perhaps this asks too much. Nevertheless, the vast literature on feeding ecology and social organization, for example, would have been easier to digest with the aid of tables and figures. Similarly, many will be frustrated by Tuttle's limited attempts to place the study of ape behavioural ecology within a broader theoretical and comparative framework. Discussions of fossil evolution, food competition and niche differentiation in the Asian apes and sexual selection in pongids are unsatisfying in the absence of considerations of major theoretical issues such as modes of speciation, the factors influencing ecological diversity and female mate choice. Finally, although some will enjoy Tuttle's light and breezy word-play, others will not be amused by his occasional use of off-colour humour.

These criticisms are minor when compared with the overall quality of this book. Tuttle has written a scholarly work that should serve as a standard reference for many years. With persistent threats endangering apes in their natural habitats, one can only hope that those years will be marked by continuing advances in the study of ape behaviour and ecology.

John C. Mitani is at the Field Research Center for Ecology and Ethology, The Rockefeller University, Millbrook, New York 12545, USA.

\section{From the outside looking in}

\section{Kurt Lambeck}

Space Geodesy and Geodynamics. Edited by Allen Joel Anderson and Anny Cazenave. Academic:1986. Pp.490. £57, $\$ 98$

THE Earth is subject to a broad spatial and temporal spectrum of deformation, ranging from global plate-tectonic motions over geological time scales of $10^{6}$ years and longer, to the nearly instantaneous and localized deformations associated with surface earthquakes. The evidence for these deformations comes from several complementary disciplines of the Earth sciences - geology, including geomorphology and geochemistry, geophysics and geodesy. The geodetic measurements provide information over a large part of the deformation spectrum, in time from a few hours to decades and longer, and in space from the short lengths of instrumental baselines to intercontinental distances. When interpreted with other geological and geophysical data, the geodetic observations give us valuable insight into the 'instantaneous' deformations and motions of the Earth.

The classical terrestrial observations have contributed greatly to the study of the dynamics of the Earth, as in the geodetic surveys of Japan and New Zealand, and the astrometric observations of the planet's rotation. The so-called space methods of geodesy - the tracking of close Earth satellites and the Moon, and the radio astrometric observations of stellar positions - have a more recent history but they have frequently been held up as a panacea for studies of the Earth's deformation. Results have, however, been slow in coming, and Space Geodesy and Geodynamics can be seen as a test of whether the methods can live up to their promises.

The book has four main parts, covering the global gravity field, space geodetic baselines, Earth rotation and dynamics of the lithosphere. Each part contains three or four chapters dealing with selected aspects of the general theme. The part dealing with the Earth's gravity field includes consideration of the results obtained from satellite orbit trajectory analysis, and from surface gravity and radar altimeter data. These observations put constraints upon models of mantle convection and lithospheric rheology and, as such, they contribute to the understanding of the long-term dynamics of the Earth. Several papers on lithospheric deformation partly address questions of lithospheric rheology that may be solved with these data. An omission here is any 